\title{
HUKUMAN MATI PASCA PUTUSAN MAHKAMAH KONSTITUSI
}

\author{
Todung Mulya Lubis ${ }^{1}$
}

\begin{abstract}
Abstrak
The criminal conduct is not only focused on the criminal law but also in sociology aspect can be observed as economic, politic and psychology aspects. Under those reflections then the author reasons that dead sentence application to the criminal actor therefore resulted injustice that also forcible. Like murder that has often occurred by poverty or neurosis. Under the author thoughts on punishment concept that has been created is correction that contained education and re-socialization aspects. Those all are shown that dead sentence aims to result deterrent not be attained. In the international fora under United Nations Organization program at 1971 and 1977 has been intentioned to abolish dead punishment had got positive responds. More regards are come from European countries who gradually adopted in to their "European Convention for the Protection of Human Rights and Fundamental Freedoms". Under the convention dead punishment abolishment initially is applied on dead sentence in peace time.
\end{abstract}

Kata kunci: hukuman mati, ham, mahkamah konstitusi, judicial review

\section{Pengantar}

Mahkamah Konstitusi (MK) dalam putusan No 2-3/PUU-V/2007 mengatakan bahwa hukuman mati tidak bertentangan dengan UUD 1945 dalam hal ini pasal 28A dan pasal 281 (1). Putusan MK ini tidak dijatuhkan dengan bulat karena tiga hakim MK, H. Achmad Roestandi, HM Laica Marzuki dan Maruarar Siahaan mengeluarkan dissenting opinion yang pada intinya mengatakan bahwa penjatuhan hukuman mati bertentangan dengan hak untuk hidup yang dijamin oleh pasal 28 UUD 1945 serta bertentangan juga dengan pasal 281 (1) yang memasukkan hak untuk hidup sebagai salah satu hak yang tak bisa dikurangi dalam keadaan apapun (non-derogable rights). Putusan yang 6:3 ini bisa dikatakan sebagai suatu putusan yang

1 Ketua Dewan Pendiri Imparsial, Wakil Presiden Kongres Advokat Indonesia (KAI), Dosen Hukum Tata Negara pada Fakultas Hukum Universitas Indonesia, alamat korespondensi: mulyalubis@1smlaw.co.id. 
bersejarah yang menggambarkan bahwa di Indonesia memang ada perbedaan pendapat yang tajam antara mereka yang pro hukuman mati dengan mereka yang anti hukuman mati. ${ }^{2}$

Persoalan diperlakukannya hukuman mati memang akan menjadi beban sejarah kita ke depan karena memang banyak sekali pertanyaan yang tak bisa dijawab. Sekarang ini banyak sekali orang yang sudah dijatuhi hukuman mati tetapi masih belum dieksekusi. Bahar bin Matar, 67 tahun, seorang narapidana pembunuhan, sudah mendekam 37 tahun di penjara tetapi sampai saat ini masih belum dieksekusi. ${ }^{3}$ Disini, apabila Bahar bin Matar akan dieksekusi maka tidak aneh jika akan ada yang berteriak bahwa betapa tidak adilnya sistem hukum kita yang bisa dikatakan menjatuhkan hukuman lebih berat dari hukuman mati itu sendiri.

Bersama Bahar bin Matar ada banyak narapidana yang mengalami nasib yang serupa. Padahal dalam hukum diperlukan kepastian hukum bagi semua termasuk bagi narapidana. Kalau penundaan pelaksanaan hukuman mati ini berlarut-larut sampai yang bersangkutan tua renta maka kita melakukan doublepunishments, dan agaknya bukan ini tujuan pemidanaan. Tetapi pihak kejaksaan melalui pedoman baku (standard operating procedures) tak akan pernah mau melakukan eksekusi sebelum terpidana mati tersebut selesai mengajukan Peninjauan Kembali (PK) dan grasi. ${ }^{4}$ Kejaksaan Tinggi tak mau dihadapkan kepada kritik dan protes yang menuduhnya tak menghormati hak-hak narapidana tersebut.

Uraian diatas menunjukkan bahwa terjadi suatu keadaan tidak tertib dalam penegakan hukum, suatu keadaan yang oleh Hakim MK Maruarar Siahaan dalam dissenting opinion disebut sebagai unsystematic law (disorder). ${ }^{5}$ Pendapat Hakim MK Maruarar Siahaan ini bukan pendapat baru, dan ketidak tertiban itupun kita bisa temukan secara mudah dalam bidangbidang hukum yang lain dimana banyak sekali inkonsistensi dan konflik antara produk perundangan-undangan baik pada tingkat nasional maupun pada tingkat daerah. Inkonsistensi dan konflik ini juga terjadi antara substansi hukum dan pelaksanaan hukum itu sendiri sehingga sesungguhnya kita mengalami kebingungan. Pada jaman Orde Baru kesimpulan yang

${ }^{2}$ Todung Mulya Lubis dan Alexander Lay, "Kontroversi Hukuman Mati", (Jakarta: Penerbit Buku Kompas, 2009), hal. 343-433.

${ }^{3}$ Lihat Koran Tempo, 4 November 2008.

${ }^{4}$ Keterangan Kepala Kejaksaan Tinggi Bali, Gortap Marbun, kepada penulis. Sekarang Gortap Marbun adalah Kepala kejaksaan Tinggi Sumatera Utara.

${ }^{5}$ Todung Mulya Lubis dan Alexander Lay, Op. Cit., hal. 406. 
diambil malah lebih ekstrim yaitu terjadinya apa yang disebut sebagai lawlessness.

\section{Jalan Buntu Penghapusan Hukuman Mati}

Putusan MK yang menolak permohonan uji materil (judicial review) hukuman mati memang merupakan putusan yang pertama dan terakhir (final). ${ }^{6}$ Tak ada upaya hukum lain yang tersedia sehingga Indonesia akan tetap berada di negara-negara yang mempertahankan hukuman mati (retentionists). Namun saya percaya bahwa perjuangan menghapuskan hukuman mati akan terus berjalan dalam berbagai bentuknya karena sesungguhnya masyarakat kita terbelah sikapnya, dan perubahan dunia ini akan memasuki juga perdebatan hukum di negeri ini. Penetrasi ilmu dan hak asasi manusia yang bergerak akan mempertajam debat hukum dan hak asasi manusia, dan disitulah kita tak akan bisa menduga apa yang bakal terjadi.

Dewasa ini memang amat banyak daftar terpidana mati yang menunggu giliran eksekusi. Dari tahun 2001 sampai tahun 2008 (November) ada sekitar 105 orang yang dijatuhi hukuman mati, dan mayoritas mereka belum dieksekusi. Mereka masih terkatung-katung menunggu nasib mereka. Dibawah ini adalah table yang menggambarkan jumlah hukuman mati yang dijatuhkan di berbagai pengadilan di Indonesia.

Tahun Vonis Mati

\begin{tabular}{|c|c|c|}
\hline No & Tahun & Jumlah \\
\hline 1 & 2001 & 17 orang \\
\hline 2 & 2006 & 17 orang \\
\hline 3 & 2003 & 12 orang \\
\hline 4 & 2000 & 10 orang \\
\hline 5 & 2004 & 10 orang \\
\hline
\end{tabular}

${ }^{6}$ Lihat Pasal 24C UUD 1945. Lihat juga pasal 10 UU No 24/2003. 


\begin{tabular}{|c|c|c|}
\hline 6 & 2007 & 10 orang \\
\hline 7 & 2005 & 9 orang \\
\hline 8 & 2002 & 5 orang \\
\hline 9 & 1998 & 5 orang \\
\hline 10 & November 2008 & 8 orang \\
\hline
\end{tabular}

Dari angka tersebut kita bisa melihat bahwa terpidana mati itu dihukum karena berbagai jenis tindak pidana seperti pembunuhan, narkotika, terorisme dan sebagainya. Dan mereka juga berasal dari berbagai negara, tidak hanya warga negara Indonesia. ${ }^{7}$ Data ini harus dicek kembali tetapi seandainya kita mengancu pada data tersebut maka kita wajar untuk bertanya apakah pidana mati ini akan terus menjadi putusan yang akan terus dijatuhkan mengingat bahwa 'hah untuk hidup' itu dijamin dan juga merupakan non-derogable human rights'? Apa yang akan dicapai dengan dijatuhkannya hukuman mati?

Melalui UU No 12/2005 Indonesia sudah meratifikasi International Covenant on Civil and Political Rights (ICCPR) yang secara tegas menjamin hak untuk hidup dalam Pasal 6 yang berbunyi:

Every human being has the inherent right to life. This right shall be protected by law. No one shall be arbitrarily deprived of his life.

ICCPR memang masih membuka ruang bagi pidana mati bagi apa yang disebut 'the most serius crimes', dan disini kita memang musti bersepakat tentang definisi the most serius crimes ini, namun demikian dengan mencantumkan 'hak untuk hidup' sebagai non-derogable human rights seharusnya perdebatan itu sudah berhenti. Ketika tindak pidana yang

${ }^{7}$ Lihat Studi Imparsial, "Jalan Panjang Menghapus Hukuman Mati di Indonesia", Jakarta, Juni 2004. 
disebut the most serius crimes itu terjadi seharusnya yang harus di pertanyakan kenapa itu terjadi? Mengapa negara gagal mencegah terjadi tindak pidana the most serius crimes tersebut? Buat saya ini pertanyaan penting sebab sebagai negara konstitusional saya berpendapat bahwa kita musti menghormati konstitusi yang merupakan ukum dasar tertinggi (the highest law of the land). Dan dari segi hak asasi manusia, UUD 1945 harus diakui telah mengalami kemajuan yang sangat bernas tentang hak asasi manusia. Coba lihat rumusan non-derogable rights di UUD 1945 dan ICCPR seperti yang tertulis dibawah ini:

Perbandingan Antara Non-derogable Rights Yang Terdapat Pada Pasal 281 Ayat (1) UUD 1945 dan ICCPR

\begin{tabular}{|c|c|c|c|}
\hline No. & Pasal 281 Ayat (1) & & ICCPR \\
\hline 1 & Hak untuk hidup; & Pasal 6 & Hak untuk hidup \\
\hline 2 & $\begin{array}{l}\text { Hak untuk tidak } \\
\text { disiksa; }\end{array}$ & Pasal 7 & $\begin{array}{l}\text { Hak untuk tidak dikenakan } \\
\text { penyiksaan atau perlakuan } \\
\text { atau hukuman lain yang } \\
\text { keji, tidak manusiawi atau } \\
\text { merendahkan martabat; }\end{array}$ \\
\hline 3 & $\begin{array}{l}\text { Hak kemerdekaan } \\
\text { pikiran dan hati } \\
\text { nurani; }\end{array}$ & Pasal 18 & $\begin{array}{l}\text { Hak atas kebebasan } \\
\text { berfikir, berkeyakinan, dan } \\
\text { beragama; }\end{array}$ \\
\hline 4 & Hak beragama; & & \\
\hline 5 & $\begin{array}{l}\text { Hak untuk tidak } \\
\text { diperbudak; }\end{array}$ & $\begin{array}{l}\text { Pasal } 8 \text { ayat } \\
\text { (1) }\end{array}$ & $\begin{array}{l}\text { Hak untuk tidak } \\
\text { diperbudak (slavery); }\end{array}$ \\
\hline 6 & & $\begin{array}{l}\text { Pasal } 8 \text { ayat } \\
\text { (2) }\end{array}$ & $\begin{array}{l}\text { Hak untuk tidak } \\
\text { diperhambakan } \\
\text { (servitude); }\end{array}$ \\
\hline 7 & $\begin{array}{l}\text { Hak untuk tidak } \\
\text { dituntut atas dasar } \\
\text { hukum yang berlaku } \\
\text { surut; }\end{array}$ & Pasal 15 & $\begin{array}{l}\text { Hak untuk tidak dituntut } \\
\text { atas dasar hukum yang } \\
\text { berlaku surut (asas Non- } \\
\text { retroactive); }\end{array}$ \\
\hline 8 & & Pasal 11 & $\begin{array}{l}\text { Hak untuk tidak dipenjara } \\
\text { karena tidak dapat } \\
\text { memenuhi kewajiban } \\
\text { berdasarkan suatu kontrak; }\end{array}$ \\
\hline
\end{tabular}


Jadi putusan MK yang tetap mempertahankan hukuman mati sungguh merupakan 'deviasi' dari apa yang tertulis dalam UUD 1945 itu sendiri. Dengan rasa hormat saya harus mengutip pendapat Hakim MK H. Achmad Roestandi dalam dissenting opinion Putusan MK No 065/PUU-11/2004 yang berbunyi:

Ada sejumlah HAM yang dijamin dalam UUD 1945. Berdasarkan Pasal 28J semua HAM itu dapat dibatasi dengan alasan tertentu, kecuali HAM yang disebutkan dalam pasal 281 (ayat (1)). Sekali lagi, harus dibaca seperti itu, sebab jika ketujuh HAM yang tercantum dalam pasal 281 (ayat (1)) masih bisa diterobos dengan pembatasan yang ditentukan dalam pasal $28 \mathrm{~J}$, berarti tidak ada lagi perbedaan antara ketujuh HAM itu dengn HAM yang lainnya. Jika demikian untuk apa ketujuh HAM itu diatur secara khusus dalam Pasal 281. Dengan kata lain untuk apa pasal 281 diadakan frasa Hak untuk tidak dituntut atas dasar hukum yang berlaku surut adalah hak asasi manusia yang tidak dapat dikurangi dalam keadaan apapun, khususnya kata-kata tidak dapat dikurangi dalam keadaan apapun adalah kata-kata yang sudah terang dan jelas, atau dengan meminjam istilah hokum fiqih Islam, merupakan sesuatu dalil yang qoth' $i$.

Pendapat senada diucapkan pula oleh Hakim MK H. Abdul Mukthie Fadjar pada perkara yang sama yang berbunyi,

..apabila UUD 1945 dalam Pasal 281 Ayat (1) merumuskan "hak untuk hidup, hak untuk tidak disiksa, hak kemerdekaan pikiran dan hati nurani, hak beragama, hak untuk tidak diperbudak, hak untuk diakui sebagai pribadi di hadapan hukum, hak untuk tidak dituntut atas dasar hukum yang berlaku surut adalah hak asasi manusia yang tidak dapat dikurangi dalam keadaan apapun" adalah tentu dengan penuh kesadaran bukti komitmen religiusitas serta kepada universalitas hak asasi manusia. Pasal 28J Ayat (2) UUD 1945 adalah untuk restriksi terhadap sejumlah HAM di luar apa yang secara limitatif telah disebutkan dalam Pasal 281 Ayat (1).

Kedua pendapat tersebut membuktikan bahwa logika konstitusional seharusnya memutuskan bahwa tak ada lagi tempat bagi hukuman mati di Indonesia. Pertanyaannya: mengapa logika itu tak diikuti oleh MK ketika 
terakhir memutuskan bahwa hukuman mati tidak bertentangan dengan UUD 1945? Kenapa Hakim MK H. Abdul Mukthie Fadjar bergeser pendapatnya dari apa yang dia ucapkan pada Putusan No 065/PUU-II/2004?

Apa yang diuraikan diatas menunjukkan bahwa perdebatan mengenai hukuman mati itu masih akan terus berlangsung, dan tak ada alasan untuk mengatakan bahwa perjuangan menghapuskan hukuman mati sudah berakhir. Dalam interaksi dunia yang semakin canggih sekarang ini kita tak dapat menafikan pengaruh yang bakal masuk, dan karenanya perubahan bukan suatu yang mustahil. UUD 1945 sendiri bukanlah dokumen ketatanegaraan yang mati tak bisa dirubah. Kondisi-kondisi yang mendorong perubahan UUD 1945 akan terbentuk dalam perjalanan sejarah ke depan.

\section{Kecenderungan Global Menghapuskan Hukuman Mati}

Pada tahun 1971 dan tahun 1977 Perserikatan Bangsa-Bangsa (PBB) mengambil inisiatif untuk mulai menghapuskan hukuman mati sebagai universal goal dimana dikatakan bahwa harus ada progressive restriction on the number of offences for which the death penalty might be imposed with a view to abolition. ${ }^{8}$ Langkah $\mathrm{PBB}$ tersebut mendapat sambutan positif terutama di Negara-negara Eropa yang dalam European Convention For The Protection Of Human Rights and Fundamental Freedoms mulai mengadopsi tujuan penghapusan hukuman mati itu dengan menghapuskan pelaksanaan hukuman mati dalam waktu damai. ${ }^{9}$ Selanjutnya langkah PBB ini ditindak lanjuti dengan keluarnya Second Optional Protocol terhadap ICCPR ${ }^{10}$ yang dalam pasal 1 berbunyi:

Wo one within the jurisdiction of a State party to the present Optional Protocol shall be executed.

Jadi langkah penghapusan hukuman mati ini semakin mendapat dukungan internasional dan terbukti sekarang bahwa jumlah negara yang menghapuskan hukuman mati itu sudah lebih banyak ketimbang yang masih

${ }^{8}$ Roger Hood, "The Death Penalty: A Worldwide Perspective", Third Edition, (Oxford: Oxford University Press, 2002), hal. 15.

${ }^{9}$ Ibid.

${ }^{10}$ Indonesia belum meratifikasi The Second Protocol ini. 
mempertahan hukuman mati. Di bawah ini adalah diagram jumlah negara dalam penerapan hukuman mati.

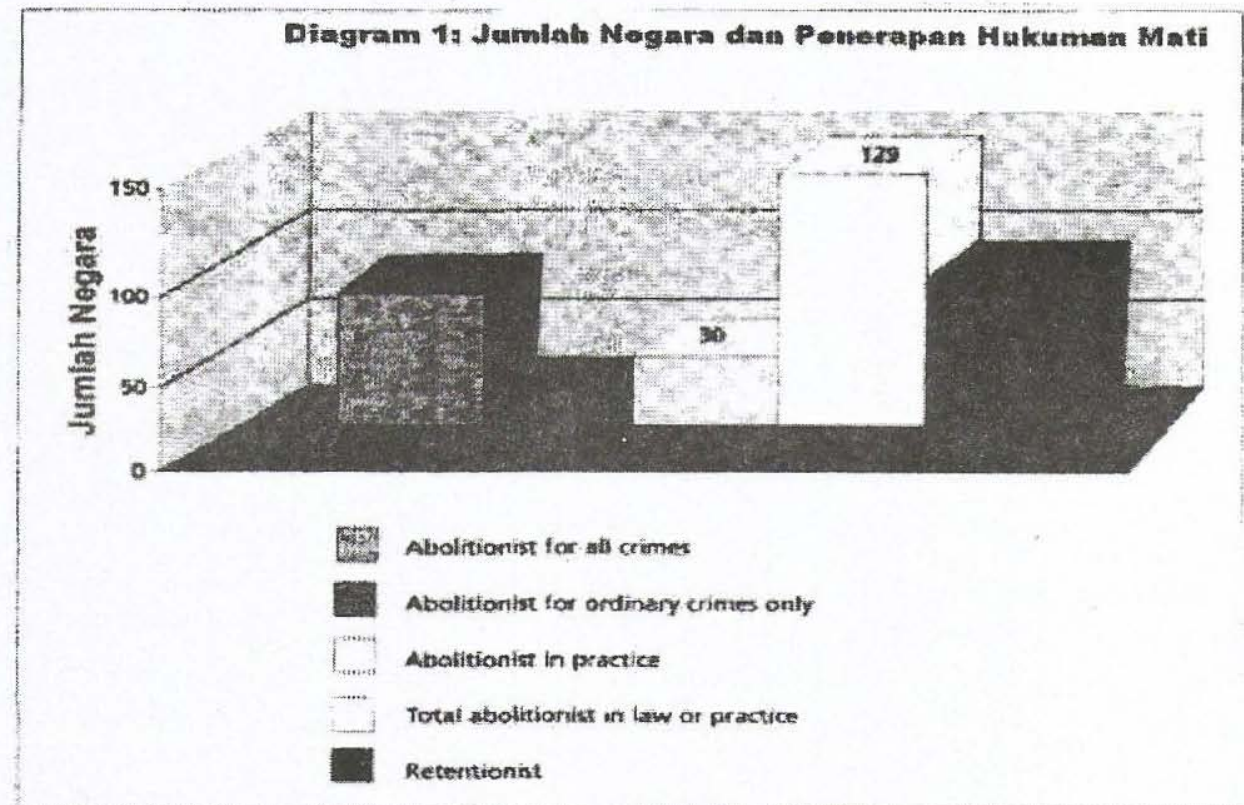

Ada dua kategori negara yang menghapuskan hukuman mati yaitu negara yang menghapus hukuman mati untuk semua tindak pidana dan negara yang secara de facto menghapus hukuman mati dengan tak melaksanakan hukuman mati. Pada table dibawah ini kita bisa melihat data tahun 1981-2006 yang membandingkan kedua kategori tersebut.

Jumlah Negara Yang Telah Menghapus Hukuman Mati 1981-2006

\begin{tabular}{|c|c|c|}
\hline Tahun & $\begin{array}{c}\text { Jumlah negara yang } \\
\text { menghapus hukuman } \\
\text { mati untuk semua tindak } \\
\text { pidana (Abolitionist for } \\
\text { all crimes) }\end{array}$ & $\begin{array}{c}\text { Jumlah negara yang telah } \\
\text { menghapus hukuman mati } \\
\text { melalui sistem hukum } \\
\text { maupun praktik (Total } \\
\text { abolitionist in law pactise) }\end{array}$ \\
\hline 1981 & 27 & 63 \\
\hline 1982 & 28 & 63 \\
\hline 1983 & 28 & 64 \\
\hline 1984 & 28 & 64 \\
\hline 1985 & 29 & 64 \\
\hline
\end{tabular}




\begin{tabular}{|l|l|l|}
\hline 1986 & 31 & 66 \\
\hline 1987 & 35 & 69 \\
\hline 1988 & 35 & 80 \\
\hline 1989 & 39 & 84 \\
\hline 1990 & 46 & 88 \\
\hline 1991 & 46 & 83 \\
\hline 1992 & 50 & 84 \\
\hline 1993 & 53 & 90 \\
\hline 1994 & 54 & 96 \\
\hline 1995 & 59 & 102 \\
\hline 1996 & 60 & 101 \\
\hline 1997 & 64 & 103 \\
\hline 1998 & 70 & 106 \\
\hline 1999 & 73 & 109 \\
\hline 2000 & 75 & 109 \\
\hline 2001 & 76 & 112 \\
\hline 2002 & 78 & 112 \\
\hline 2003 & 79 & 118 \\
\hline 12004 & 84 & 120 \\
\hline 2005 & 86 & 122 \\
\hline 2006 & 88 & 129 \\
\hline
\end{tabular}

Sumber : Amnesty Internasional

Kalau tabel diatas kita buatkan dalam bentuk diagram maka akan terlihat bahwa ada kecenderungan yang meningkat dalam menghapuskan hukuman mati baik secara dejure maupun de facto. 


\section{Diagram 2: Tren Dunia International dalam Menghapus Hukuman Mati, 1981-2006}

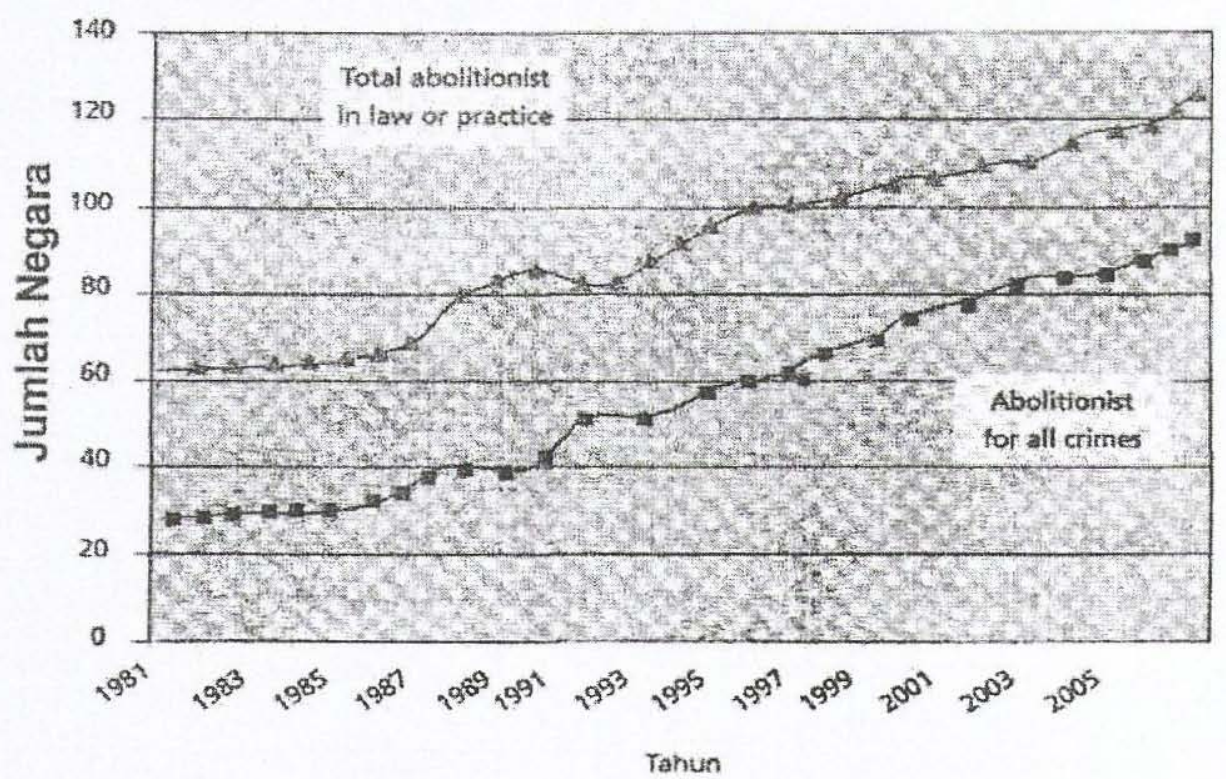

\section{Himbauan untuk Moratorium}

Himbauan untuk moratorium adalah himbauan yang tak popular karena memang sentiment public yang kita bisa baca adalah kuatnya dukungan terhadap hukuman mati. Tetapi sebagai orang yang belajar mengenai konstitusi dan hak asasi manusia saya akan terus menghimbau penghapusan hukuman mati kalau tak bisa secara de jure tentu secara de facto. Kecenderungan global menghapuskan hukuman mati akan juga datang mempengaruhi wacana kita berbangsa dan bernegara, dan pada gilirannya saya percaya bahwa publik juga akan semakin sadar bahwa persoalan kejahatan itu tak sesederhana yang kita bayangkan. Pembunuhan, misalnya, sering sekali terjadi karena kemiskinan atau ketidakwarasan. ${ }^{11}$ Kasus narkotika, misalnya, apakah terjadi tanpa dukungan sindikasi nasional dan internasional? Kenapa sindikasinya tak terberantas sementara pengedar yang hanya berupa mata rantai yang menjadi terpidana mati? Mereka ini juga

1 Kasus Ryan di Jawa Timur menunjukkan bahwa ada orang-orang yang kejam membunuh sekian banyak orang, tetapi dalam kasus ini pun kita bisa bertanya apakah tak ada kelainan jiwa pada Ryan? Apakah dia bertindak dalam keadaan sadar? 
adalah pelaku-pelaku yang datang dari latar belakang keluarga miskin. ${ }^{12}$ Lalu kasus tindak pidana terorisme buat saya adalah tindak pidana yang digerakkan oleh ideologi politik yang bisa jadi sebagai protes dari ketertindasan politik dan ekonomi. ${ }^{13}$ Jadi sebuah kejahatan kejam yang merupakan tindak pidana mandiri tanpa sebab adalah suatu hal yang sulit dicerna dan diterima. Tindak pidana bukanlah semata-mata soal hukum pidana tetapi secara sosiologi dia adalah soal ekonomi, politik dan psikologis. Karenanya, menimpakan hukuman mati hanya kepada pelaku justru menimbulkan ketidakadilan yang tak kalah kejamnya. Tentu bukan maksud saya untuk tidak menghukum, tetapi hukuman yang akan dijatuhkan seyogyanya bukanlah hukuman mati.

Selain hukuman mati itu bertentangan dengan 'hak untuk hidup' yang sifatnya non-derogable seperti yang diatur dalam pasal 281 (1) UUD 1945 ada beberapa alasan yang bisa dikemukakan disini yaitu, pertama, system pidana dimanapun bukanlah sistem yang sempurna. Kita mengenal apa yang disebut sebagai 'fallibility of criminal justice system ${ }^{14}$ Sangat mungkin terjadi kesalahan seperti yang dulu pernah dialami oleh Sengkon dan Karta, dan sekarang dialami lagi oleh Devid dan Kemat di Jawa Timur. ${ }^{15}$ Di negaranegara maju juga kesalahan ini terjadi karena memang tak mudah mendapatkan bukti-bukti yang sangat sahih tentang terjadinya tindak pidana. Jadi penjatuhan hukuman mati seharusnya tak usah dilakukan karena sangat berbahaya karena sifatnya yang irreversible, tak bisa dirubah ketika sudah dieksekusi. Bagaimana mungkin menghidupkan lagi seseorang yang tak terbukti bersalah ketika eksekusi sudah dilakukan? Prof.Jeffrey Fagan yang bersaksi di MK pada tanggal 2 Mei 2007 mengatakan bahwa:

Since 1976, when the US Supreme Court ended its moratorium on capital punishment, 123 defendants who had received death sentences have been exonerated. That is, they have been cleared of all charges against them. During this period of time, 1,057

${ }^{12}$ Penulis membela Andy Chan dalam kasus Judicial Review UU No 22/1997 tentang Narkotika. Andy Chan adalah anak keluarga miskin di Sidney, Australia, yang terjerembab dalam mata rantai narkotika.

${ }^{13}$ Amrozi dkk bukanlah pelaku tindak pidana terror yang berjalan sendiri. Kalau benar bahwa Amrozi merupakan bagian dari organisasi yang disebut Jemaah Islamiyah yang dituduh ikut mendalangi terorisme, maka jelas Amrozi tak bertindak atas kemauannya sendiri.

${ }^{14}$ Todung Mulya Lubis dan Alexander Lay, Op. Cit., hal. 337-338.

${ }^{15}$ Lihat, Todung Mulya Lubis, "Balada David dan Kemat", Kompas, 17 Oktober 2008. 
persons have been executed in the US. Accordingly, for every 100 persons executed, at least one innocent person has been released from death row. The more that societies use the death penalty, the greater the likelihood there will be an execution of an innocent person.

Kenapa hal itu terjadi? Menurut Jeffrey Fagan hal itu terjadi karena kesalahan umum (common errors) yang terjadi dalam sistem peradilan yaitu:

The reasons so many were re-sentenced or released were "serious error" in their trials. S serious error is the type of error that negates the reliability of the facts of guilt at trial. These error weaken public confidence in the law. The most common error were:

- Incompetent defense counsel (37\% of all reversals);

- Prosecutors who suppressed or withheld evidence that the defendant was either innocent or was not fully culpable for his acts $(16 \%)$;

- Misconduct by the police, who also hid evidence, failed to properly interrogate witness who proved later to be unreliable and withheld other evidence ( $3 \%$ of all reversals);

- Erroneous identification by eyewitness;

- False accusations byjailhouse informants.

Alasan kedua yang sering dikemukakan adalah fakta bahwa hukuman mati tak berhasil menghentikan kejahatan, tak menimbulkan efek jera (deterrent effect). Dari berbagai studi yang dilakukan di banyak negara bisa disimpulkan bahwa kejahatan itu tak terjadi bukan karena ketakutan akan hukuman mati tetapi justru karena ketakutan akan tertangkap. Hukuman mati itu tak menjuadi pertimbangan ketika turut serta dalam melakukan kejahatan. Hanya saja ketika ada indikasi bahwa aparat kepolisian akan melakukan penangkapan, maka tindak kejahatan itu berhenti dilakukan. Artinya, effektivitas pihak aparat penegak hukumlah yang mampu menghentikan atau mengurangi angka kejahatan. Dalam kasus narkotika di Indonesia, ${ }^{16}$ misalnya, perkembangan kasusnya menunjukkan peningkatan meski ada ancaman hukuman mati seperti yang kita bisa lihat pada diagram dibawah ini:

${ }^{16}$ Todung Mulya Lubis dan Alexander Lay, Op. Cit., hal. 66. 


\section{Diagram 3: Perkembangan Jumlah Kasus Narkotika dan Psikotropika 2001-2005}

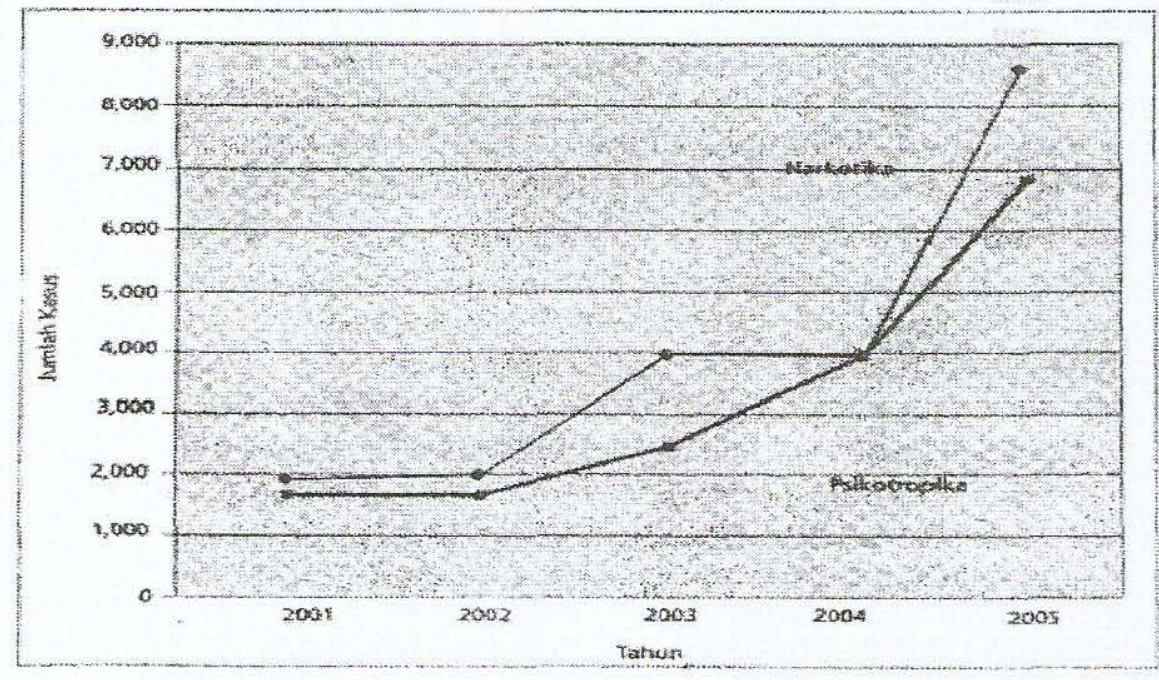

\section{Diagram 4: Perbandingan Laju Pembunuhan di Eropa dan Amerika Serikat}

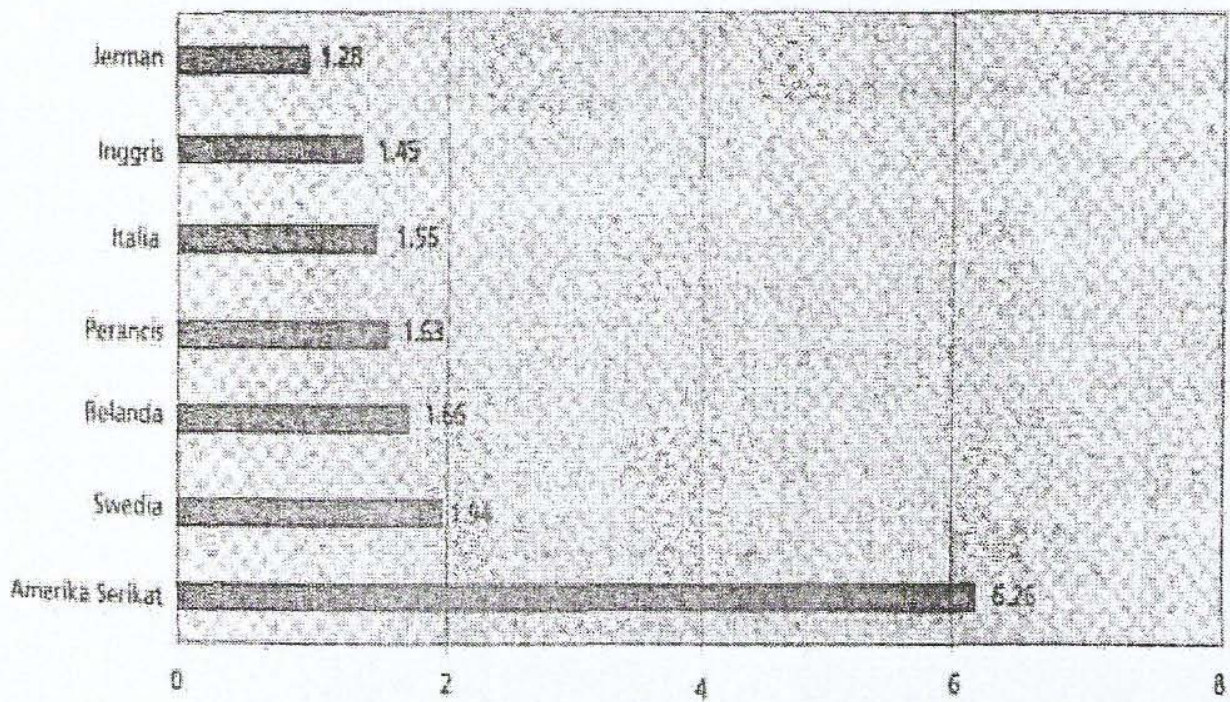

Lumbah Pambwotan tiap 100000 orang (rata-fata setiap tahun, $1997-1909$ ) 
Di beberapa negara Eropa dan Amerika, misalnya, kita melihat perbedaan yang menarik dimana laju tindak pidana pembunuhan di Amerika yang di banyak negara bagian masih menganut hukuman mati, tindak pidana pembunuhannya cukup tinggi meski ada ancaman hukuman mati. Sementara di negara-negara Eropa seperti Jerman, Inggris, Italia, Perancis, Belanda dan Swedia yang tak lagi menganut hukuman mati justru laju tindak pidana pembunuhannya rendah. ${ }^{17}$

Kesemuanya ini menunjukkan bahwa tujuan hukuman mati yang ingin menimbulkan penjeraan (deterrent) tak tercapai. Apakah kecenderungan ini tak mengharuskan kita untuk bertanya ulang tentang relevansi hukuman mati dalam sistem hukum kita? Saya termasuk orang yang akan terus bertanya tentang hal ini karena dipertahankannya hukuman mati menunjukkan isolasi intelektual yang berbahaya bagi perkembangan hukum dan hak asasi manusia di negeri ini.

Alasan ketiga yang harus dipertimbangakan disini adalah tentang alternative pemidanaan yang musti disosialisasikan. Dalam berbagai sistem hukum dikenal hukuman berat yang tak mencabut nyawa terpidana seperti hukuman seumur hidup (life sentence) dan hukuman seumur hidup tanpa remisi (life sentence without parole). Apabila alternative hukuman ini diketahui oleh publik, maka bukan mustahil bahwa dukungan public terhadap hukuman mati akan berkurang. Jeffrey Fagan mengatakan dalam kesaksiannya di MK pada tanggal 2 Mei 2007 bahwa dukungan publik cenderung berkurang ketika diketahui ada alternatif hukuman lain yang juga cukup berat, malah lebih berat dari hukuman mati itu sendiri. ${ }^{18}$ Saya kira publik tak banyak yang tahu tentang alternatif hukuman yang ada dalam sistem pemidanaan kita.

Dalam konteks ini mungkin kita perlu meninjau kembali tujuan pemidanaan, yaitu, apakah pemidanaan itu untuk suatu pembalasan dendam (retributive), atau untuk mendidik terpidana untuk berubah menjadi manusia yang berkelakuan baik? Konsep pemidanaan yang kita bangun adalah konsep pemasyarakatan yang didalamnya ada elemen pendidikan dan resosialisasi. Dalam menjalani pemidanaan itulah para terpidana dididik untuk merubah hidup mereka menjadi manusia yang berkelakuan baik dan taat hukum. Sebagai tambahan mungkin perlu pula dikemukakan bahwa pemaafan adalah suatu tindakan mulia yang dianjurkan oleh semua agama, malah dealam penafsiran yang liberal selalu dikatakan bahwa manusia itu tak berhak

${ }^{17}$ Ibid., hal. 67.

${ }^{18}$ Kesaksian Prof. Jeffrey Fagan di Mahkamah Konstitusi, 2 Mei 2007. Keterangan ini juga diucapkan Prof. Jeffrey Fagan ketika berbincang dengan penulis. 
mencabut nyawa orang lain karena yang berhak mencabut nyawa manusia itu adalah Tuhan. Tanpa bermaksud untuk turut dalam perdebatan teologis tersebut, saya juga berpendapat bahwa manusia itu memiliki keterbatasan. Menghabisi nyawa seseorang adalah tindakan tak beradab. Jangan tindakan tak beradab tersebut dibalas dengan tindakan yang sama tak beradabnya.

\section{Penutup}

Jalan memang masih panjang, dan masa depan tak selamanya bisa diperkirakan. Namun kecenderungan peradaban yang menjunjung tinggi hak asasi manusia serta menghapuskan hukuman mati akan semakin menguat, dan saya percaya angin perubahan itu juga sedang berhembus ke kawasan ini. Setelah ditandatanganinya Asean Charter di kawasan ini akan dibentuk suatu Human Rights Commission. Kita berharap bahwa dari Human Rights Commission akan keluar angin perubahan seperti yang terjadi di Eropa dan Afrika. Kita berharap bahwa perjalananh sejarah akan membawa perubahan dimana mungkin saja suatu waktu kelak akan ada Human Rights Court di kawasan Asean ini.

Putusan MK yang mengatakan bahwa hukuman mati tak bertentangan dengan konstitusi memang suatu langkah mundur. Tapi sejarah kan tak selamanya ditandai dengan langkah mundur. Ada kalanya, dan sering terjadi, setelah langkah mundur terjadi langkah maju. Mari kita sama-sama menunggu. 


\section{Daftar Pustaka}

Hood, Roger. The Death Penalty: A World Wide Perspective, $3^{\text {rd }}$ edition, Oxford: Oxford University Press, 2002.

Jalan Panjang Menghapus Hukuman Mati Di Indonesia, Jakarta: Studi Imparsial, 2004.

Kontroversi Hukuman Mati, "Koran Tempo", 4 November 2008.

Lubis, Todung Mulya dan Alexander Lay, Kontroversi Hukuman Mati, Jakarta: Penerbit Buku Kompas, 2009. , Balada David dan Kemat, "Kompas", 17 Oktober 2008.

Undang-undang Dasar 1945.

Undang-undang Nomor 24 Tahun 2003 tentang Mahkamah Konstitusi. 